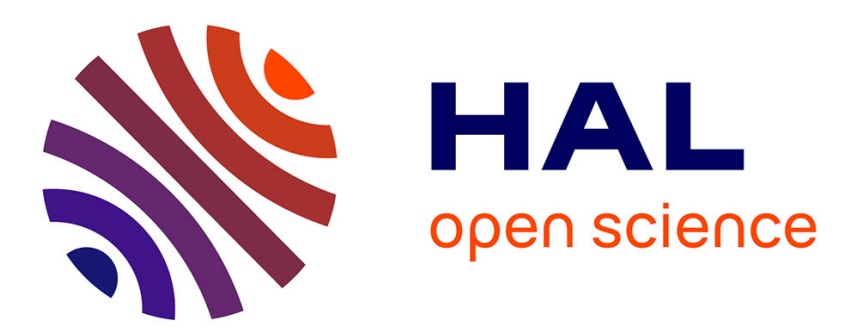

\title{
Development of a Granular Cohesive Model for Rolling Contact Fatigue Analysis: Crystal Anisotropy Modeling
} Jean-Philippe Noyel, Fabrice Ville, Anthony Gravouil, Philippe Jacquet, Christophe Changenet

\section{- To cite this version:}

Jean-Philippe Noyel, Fabrice Ville, Anthony Gravouil, Philippe Jacquet, Christophe Changenet. Development of a Granular Cohesive Model for Rolling Contact Fatigue Analysis: Crystal Anisotropy Modeling. Tribology Transactions, 2015, 10.1080/10402004.2015.1087076 . hal-01298191

\section{HAL Id: hal-01298191 \\ https://hal.science/hal-01298191}

Submitted on 23 Aug 2021

HAL is a multi-disciplinary open access archive for the deposit and dissemination of scientific research documents, whether they are published or not. The documents may come from teaching and research institutions in France or abroad, or from public or private research centers.
L'archive ouverte pluridisciplinaire HAL, est destinée au dépôt et à la diffusion de documents scientifiques de niveau recherche, publiés ou non, émanant des établissements d'enseignement et de recherche français ou étrangers, des laboratoires publics ou privés. 


\title{
Development of a Granular Cohesive Model for Rolling Contact Fatigue Analysis: Crystal Anisotropy Modeling
}

\author{
J.-P. Noyel ${ }^{a}$, F. Ville ${ }^{b}$, P. Jacquet ${ }^{a, c}$, A. Gravouil ${ }^{b, d}$, and C. Changenet ${ }^{a}$ \\ aLabECAM - matériaux et structures, École catholique des arts et métiers (ECAM) - Lyon, Université de Lyon, Lyon, France; 'baboratoire de Mécanique \\ des Contacts et des Structures (LaMCoS), Unité Mixte de Recherche (UMR) 5259, Institut national des sciences appliquées (INSA) de Lyon, Université de \\ Lyon, Villeurbanne, France; 'Laboratoire Bourguignon des Matériaux et Procédés (LaBoMaP), Equipe d'accueil (EA)3633, Arts et Metiers ParisTech Cluny, \\ Cluny, France; ${ }^{d}$ Institut universitaire de France, Paris, France
}

\begin{abstract}
In rolling contact fatigue (RCF), failure mechanisms are known to be very sensitive to material microstructure. Yet, among the different numerical models developed to predict RCF life, few models use a microstructure representation. A granular cohesive finite element model has been developed to simulate progressive damage of a structure subject to RCF and to investigate failure initiation mechanisms. This article focuses on the implementation of crystal elasticity in the model. The numerical analysis of a representative volume element (RVE) validates the use of cubic elasticity to represent crystal behavior. The influence of the RVE size and the influence of boundary conditions applied on the RVE are evaluated in the finite element approximation framework. With regard to the implementation of cubic elasticity in the RCF model, the generation of stress singularities at triple junctions is first highlighted. Then the average value of the intergranular shear stress is proved to be mesh size independent and therefore can be used as damage criterion. Finally, the influence of crystal elasticity on microcrack distribution is presented.
\end{abstract}

\section{Introduction}

Contact fatigue is the predominant mode of failure of components subjected to a repeated contact pressure, like rolling element bearings or gears. This phenomenon is known as rolling contact fatigue (RCF). A large number of models (described in Sadeghi, et al.'s (1) review), have been developed to predict RCF, but there is currently no complete predictive life model, and understanding RCF failure mechanism remains a significant challenge. Different reasons can explain this difficulty: (1) the complexity and variety of RCF manifestations and failure mechanisms as highlighted by Olver (2) most of the theoretical models (Keer and Bryant (3)) include an initial crack and are consequently limited to the prediction of the propagation stage, because crack initiation is being investigated. The extended finite element method (X-FEM) has been used to simulate crack propagation (Trollé, et al. (4)). Furthermore, X-FEM combined with Dang Van's criterion is used for crack initiation and propagation in the fretting case in 2D and 3D (initiation is based on the distribution of Dang Van's crack nucleation risk; Pierres, et al. (5)). Another key point in the difficulty in predicting RCF life is the influence of material microstructure. As in classical structural fatigue, the material microstructure has a significant role in RCF failure mechanisms.

This study focuses on the role of microstructure in RCF failure initiation mechanisms. In the spirit of models proposed by Sadeghi and coworkers (Raje, et al. (6)), an FEM is developed to simulate the progressive damage of a structure subject to rolling contact. The developed model is based on a granular representation and a cohesive zone method is used to represent grain boundaries (GBs): indeed, in the proposed approach, intergranular failure initiation is assumed. In the literature, a micromechanical model based on a collection of cohesive zones embedded between each finite element (cohesive-volumetric approach) has already been used (Blal, et al. (7)). The overall macroscopic elastic behavior is then obtained using homogenization techniques. In this article, this approach is extended to a collection of cohesive zones embedded between each grain of the polycrystalline material.

In a first step, isotropic elasticity is used to represent the grain mechanical behavior. However, a polycrystalline material, like steel, usually exhibits an anisotropic behavior at the grain scale (mesoscopic level). Therefore, in order to make the developed model more representative of the material microstructure, the anisotropic grain behavior is implemented. Crystal elasticity has been frequently investigated in the past (Sauzay (8)) and, recently, Paulson, et al. (9) applied crystal elasticity to RCF. Concerning RCF, Alley and Neu (10) also investigated a model with crystal plasticity. However, it seems that crystal elasticity has never been associated with damage modeling and cohesive methods in RCF analysis.

In this article, the key features of the model are first described: rolling contact modeling at the grain level, introduction of cohesive elements to represent GB, and damage modeling. An example of microcrack distribution concludes this first section. Then the anisotropic crystal behavior and cubic elasticity are presented. The article focuses on the behavior of an aggregate of crystals called 


\section{Nomenclature}

$\begin{aligned} \mathrm{a}= & \text { Hertzian contact half width } \\ {[\mathrm{C}]=} & \text { Stiffness matrix } \\ D= & \text { Damage variable } \\ \Delta D= & \text { Maximum damage increment between two FEA } \\ E= & \text { Young's modulus } \\ F_{x}= & \text { Computed reaction force ( } x \text { direction) on the RVE } \\ G= & \text { Shear modulus } \\ K= & \text { Bulk modulus } \\ K_{n}= & \text { Normal stiffness of cohesive elements } \\ K_{t} & =\text { Tangential stiffness of cohesive elements } \\ K_{t 0} & =\text { Initial tangential stiffness of cohesive elements } \\ L_{\mathrm{HP}} & =\text { Distance of the moving of the Hertzian pressure } \\ m & =\text { Material parameter used in damage law } \\ N & =\text { Number of cycles } \\ N_{\mathrm{FEA}}= & \text { Number of FEA } \\ N_{\mathrm{sub}}= & \text { Number of divisions (substep) of an FEA } \\ P= & \text { Hertzian pressure } \\ P_{0}= & \text { Maximum Hertzian pressure } \\ {[\mathrm{S}]=} & \text { Compliance matrix }\end{aligned}$

representative volume element (RVE). Finally, the influence of crystal anisotropy on RCF and mesh size are discussed.

\section{Finite element model}

The purpose of the present model is to simulate the progressive damage from initial undamaged state to the initiation of first microcracks. Figure 1 illustrates the approach used in this study: (1) a granular cohesive model is built with mechanical properties equivalent to an undamaged GB; (2) the rolling contact cycle is simulated by moving a Hertzian pressure on the granular model; (3) following the finite element analysis (FEA), a damage rate is computed for each GB and a new damage value is evaluated; and (4) mechanical properties are changed in accordance with the new damage value. As intergranular failure initiation is assumed, damage is applied on the tangential stiffness of cohesive element $\left(K_{t}\right)$. Then steps 2 to 4 are repeated to simulate the progressive deterioration of the GB. First, a computationally efficient, 2D plane-strain model is developed to analyze the influence of different parameters such as mechanical properties, operating contact conditions, material microstructure, etc. ANSYS Academic Research, Release 14.5, is used.

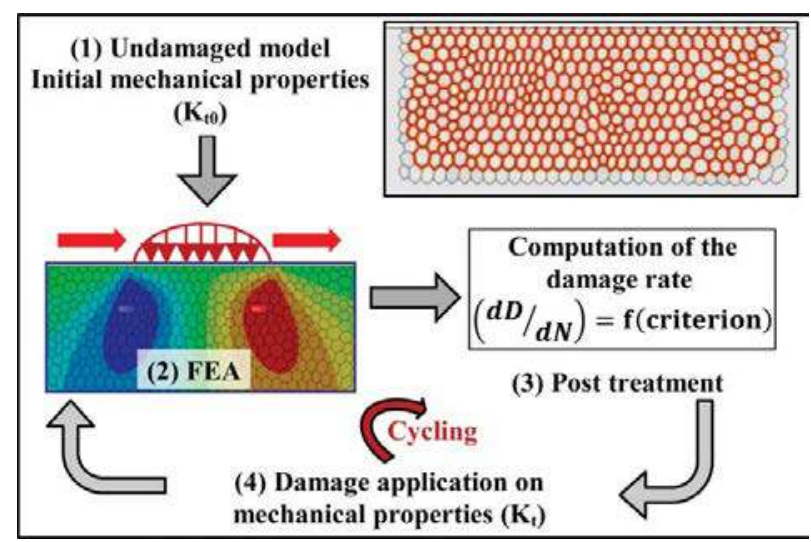

Figure 1. Damage simulation method.
Time $=$ Dimensionless parameter defining the position of the Hertzian pressure during the FEA

$u_{\mathrm{n}}=$ Normal relative displacement of cohesive elements

$u_{\mathrm{t}}=$ Tangential relative displacement of cohesive elements

$\mathrm{X}_{\mathrm{i}}=$ Position of the Hertzian pressure center corresponding to step number $i+1$ of the FEA

$\delta_{\mathrm{x}}=$ Prescribed displacement ( $x$ direction) on the RVE

$\delta_{\mathrm{y}}=$ Computed displacement ( $y$ direction) on the RVE

$\lambda=\quad$ Size of the RVE: dimensionless parameter

$v=$ Poisson's ratio

$\sigma=\quad$ Normal cohesive stress

$\sigma_{\mathrm{r}}=$ Material parameter used in damage law

$\tau=$ Tangential cohesive stress

$\Delta \tau=$ Damage criterion: variation in ISS during an FEA

\section{Subscripts}

$r=$ Component evaluated with Reuss's theory

$v=$ Component evaluated with Voigt's theory

\section{Rolling contact cycle modeling at the mesoscopic scale}

Different numerical methods are used to represent the material microstructure. A first method consists of using hexagons in a 2D model (Romero de la Osa, et al. (11); Estevez, et al. (12)). Another method frequently observed consists of using Voronoi tessellation (Warner and Molinari (13); Bomidi, et al. (14)).

In the present work, a $2 \mathrm{D}$ approach similar to the Voronoi method has been used. The size of each grain is approximately $25 \mu \mathrm{m}$, which is representative of bearing steels. The boundary conditions must be applied far enough from the area of interest in order to avoid modifying the stress field in this area. To reduce computational time, the granular representation is applied only on a small part of the model. Each grain is meshed with classical finite elements (quadratic elements; Fig. 2a).

The rolling contact cycle is simulated by moving a Hertzian pressure (Eq. [1]) upon the granular representation on a distance $L_{\mathrm{HP}}$ (Fig. 3), as in Keer and Bryant (3), Bhargava, et al. (15), and Warhadpande, et al. (16). Tangential surface stress induced by friction or pressure profile modifications due to roughness, for example, can also be implemented.

$$
P(x)=P_{0} \sqrt{1-(x / a)^{2}} .
$$

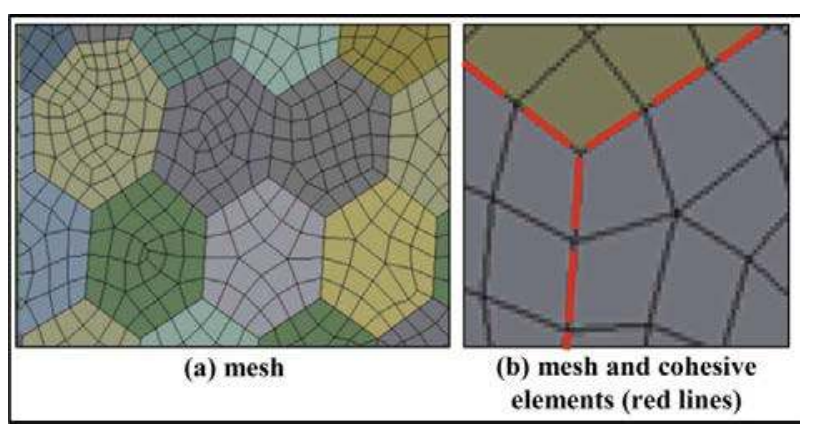

Figure 2. Mesh and cohesive elements. 


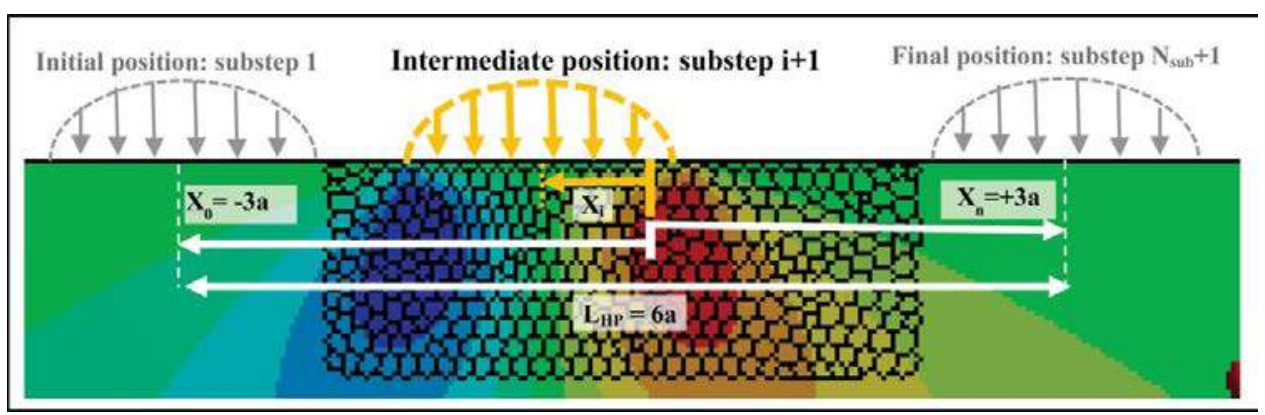

Figure 3. Rolling cycle modeling (orthogonal shear stress distribution correspond to substep $i+1$ ).

The spatial discretization is controlled by the parameter $N_{\text {sub. }}$ The load case is divided in $N_{\text {sub }}+1$ substeps. A first simulation is performed for the initial position $X_{0}$ of the Hertzian pressure center and then $N_{\text {sub }}$ other simulations are performed by moving the pressure by a distance $L_{\mathrm{HP}} / N_{\text {sub }}$ between each simulation. An example $\left(L_{\mathrm{HP}}=6 a\right)$ is given in Fig. 3. The position of the Hertzian pressure is defined by a dimensionless parameter noted Time defined in Eq. [2]. The beginning of the first FEA corresponds to Time $=0$ and the end of the first FEA corresponds to Time $=1$.

$$
\text { Time }=j \times \frac{i-1}{N_{\text {sub }}} \quad \begin{array}{ll}
1 \leq i \leq N_{\text {sub }}+1: \text { substep number } \\
1 \leq N_{F E A}: \text { FEA number }
\end{array}
$$

\section{Cohesive zone model}

A natural way to model GB is to use cohesive zone models (Xu and Needleman (17); Nguyen, et al. (18); Luther and Könke (19)). In this study, contact elements are used (ANSYS denomination: Contact172 and target170; ANSYS (20)). Cohesive elements are inserted between each grain (Fig. 2b). The cohesive stresses (normal, $\sigma$, and tangential, $\tau$ ) are linked to the relative

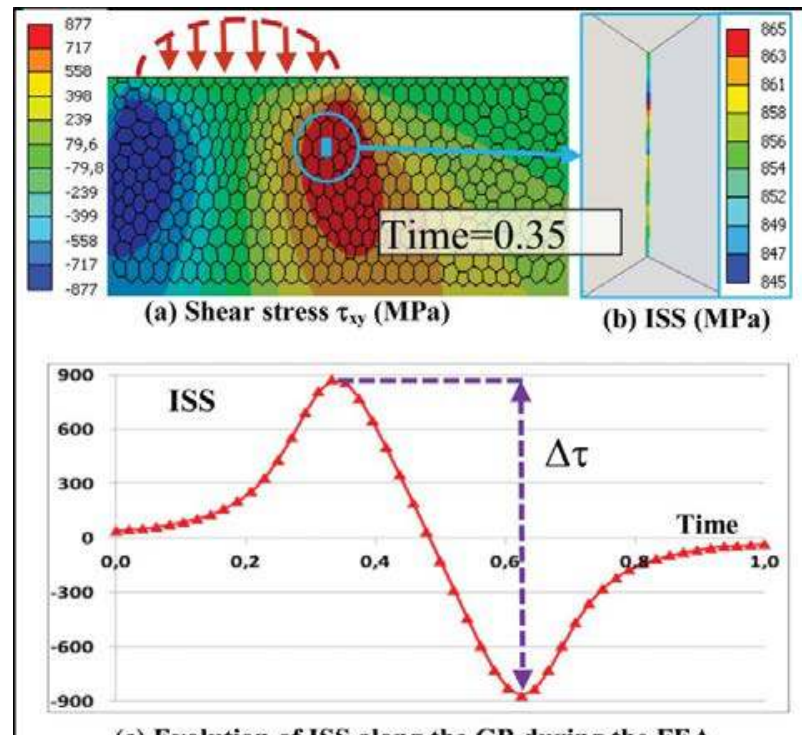

(c) Evolution of ISS along the GB during the FEA

Figure 4. ISS and evaluation of the damage criterion. displacements by a linear law (Eq. [3]).

$$
\sigma=K_{n} \times u_{n} \tau=K_{t} \times u_{t} .
$$

Cohesive element insertion can slightly modify the structural response by changing its global stiffness. The initial slope of the cohesive law must be carefully chosen. On the one hand, a too small value of this parameter decreases the global stiffness of the structure but, on the other hand, a large value could lead to numerical instabilities. The influence of this parameter was investigated by Espinosa and Zavattieri (21) and Blal, et al. (7). It has been demonstrated that for values above $10^{10} \mathrm{MPa} / \mathrm{mm}$ the model behavior is no longer affected by cohesive elements (Noyel, et al. (22)). As a conclusion, in the present study, the normal stiffness $K_{n}$ and the initial tangential stiffness $K_{t 0}$ are set to $10^{10} \mathrm{MPa} / \mathrm{mm}$.

\section{Damage modeling}

To model the progressive deterioration of the GB, the concept of damage introduced by Kachanov (23) and described by Lemaitre, et al. (24) is used and applied to the GB, which is considered as a single entity. A scalar variable $D$ characterizes damage. After each FEA, the damage rate is computed for each GB.

Due to the assumption of GB failure initiation, the variation in the intergranular shear stress (ISS) during the FEA, $\Delta \tau$, is used as a damage criterion. Figure 4 illustrates the evaluation of this criterion. In this figure, a GB located in the area of maximum orthogonal shear stress is analyzed. Figure 4a represents orthogonal shear stress distribution during the FEA (Time = 0.35). The distribution of the ISS along this GB is presented in Fig. $4 \mathrm{~b}$. Figure $4 \mathrm{c}$ represents the evolution of the average value

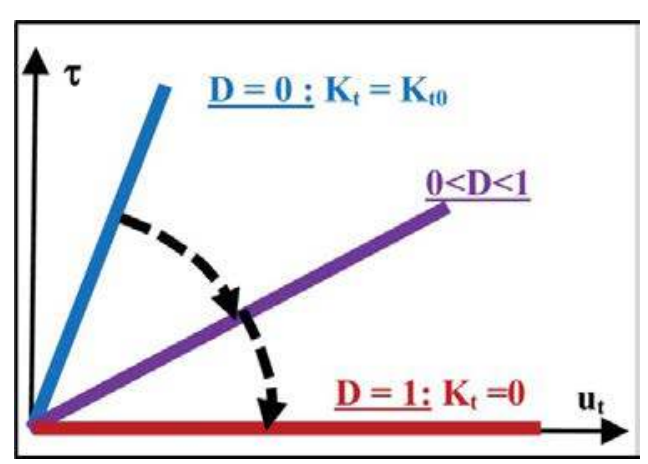

Figure 5. Damage application on the tangential cohesive stiffness. 
Table 1. Main characteristics of the model.

\begin{tabular}{lcc}
\hline Hertzian Pressure & $P_{0}=3,500 \mathrm{MPa}$ & $a=200 \mu \mathrm{m}$ \\
Granular area & Size: $800 \mu \mathrm{m} \times 300 \mu \mathrm{m}$ & \\
Grain size & $25 \mu \mathrm{m}$ & $N_{\text {sub }}=48$ \\
Load case & $L_{\mathrm{HP}}=1,200 \mu \mathrm{m}$ & \\
Cycling & $\Delta D=0.1$ & \\
\hline
\end{tabular}

along the GB of this ISS during the FEA. The variation in this average value, $\Delta \tau$, is used as a damage criterion.

The damage evolution is computed according to the damage law (Eq. [4]). $N$ represents the number of cycles; $\sigma_{r}$ and $m$ are material parameters. In this first approach, the parameters defined by Raje, et al. (6) ( $m=10.1$ and $\left.\sigma_{r}=6,113 \mathrm{MPa}\right)$ are used.

$$
\frac{d D}{d N}=\left[\frac{\Delta \tau}{\sigma_{\mathrm{r}}(1-D)}\right]^{m}
$$

Because the GB is considered as a single entity, the damage variable $D$ is applied on the tangential stiffness of all cohesive elements along the GB (Fig. 5). A natural approach consists of applying damage directly on the tangential stiffness (Eq. [5]), but with this method the effect of damage on the ISS is insignificant (Noyel, et al. (22)). Therefore, in this study, damage is applied on the tangential stiffness but with a specific formulation in order to have a direct impact on the ISS (Eq. [6]); the method is presented in Noyel, et al. (22).

$$
\begin{gathered}
K_{t}=K_{t 0} \times(1-D) \\
K_{t}=K_{t 0} \times \frac{1-D}{1+D \times K_{t 0} /\left(K_{s} / 2\right)} \Leftrightarrow \tau=\tau_{0} \times(1-D) \\
\left(K_{s}=\text { Shear modulus } / \text { Grain size }\right) .
\end{gathered}
$$

The computational time required for simulating all life cycles would be excessive. Therefore, a "jump in cycles" method similar to the one proposed by Lemaitre and Desmorat (25) is used (Noyel, et al. (22)). Using this method, an FEA corresponds to a block of life cycles. The main assumption is that damage is constant during each block. This method is controlled by the parameter $\Delta D$, which represents the maximum damage increment between two blocks. Its influence on the numerical life cycles has been investigated and a convergence has been found for $\Delta D=0.1$.

The main characteristics of the RCF model used in this article are summarized in Table 1.

\section{Microcrack distribution with isotropic elasticity}

The damage value associated with each GB increases after each FEA. When the damage value is equal to one at a GB, the GB is considered as a microcrack. Figure 6 illustrates failure initiation. The first microcrack (Fig. 6b) is located in the area of maximum orthogonal shear stress (Fig. 6a). The position of this first microcrack depends on granular geometry. This first microcrack affects the stress distribution and, as a result, other microcracks appear in a close area around the first microcrack After initiation of several localized microcracks, some of them coalesce to produce longer cracks (Fig. 6c).

The localization of first microcracks is in good agreement with observations. The initiation depth of cracks was shown to correspond to the depth of maximum orthogonal shear stress (Longching, et al. (26); Qing, et al. (27)). However, it is difficult to proceed to experimental and model comparisons of the number of life cycles based on microcrack initiation. Indeed, RCF depends on a large number of parameters: the influence of inclusions, surface roughness, and operating conditions was investigated by Nélias, et al. (28); recently, Rabaso, et al. (29) showed the influence of material properties and heat treatments and Allison, et al. (30) demonstrated the beneficial effect of compression residual stresses. The influence of these parameters has to be modeled for accurate prediction of the fatigue life. However, the order of magnitude of life cycles described in Fig. 6 is in accordance with results measured by Nélias, et al. (28).

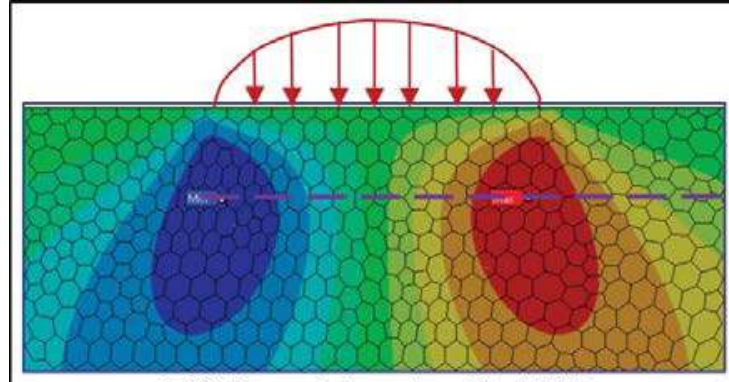

(a) Orthogonal shear stress (first FEA)

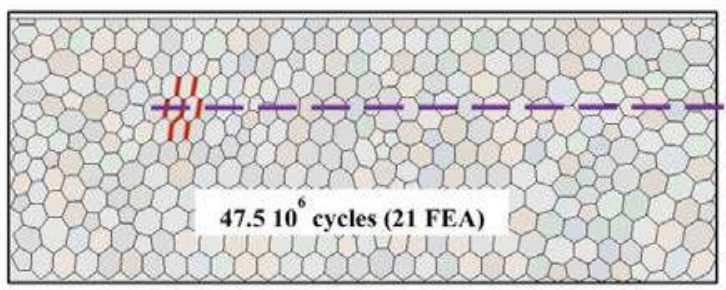

(c) Coalescence of micro-cracks

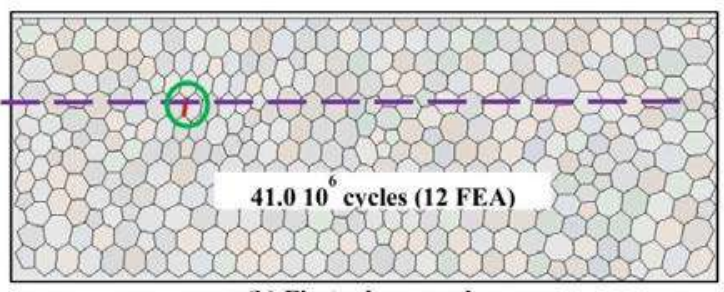

(b) First micro-crack

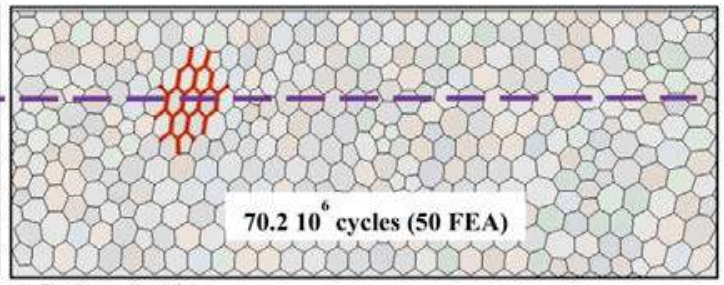

70.210 cycles (50 FEA

Figure 6. Localization of first microcracks. 
Table 2. Stiffness matrix components and young's moduli of iron $\alpha$.

\begin{tabular}{lcccc}
\hline $\mathrm{C}_{11}$ & $\mathrm{C}_{12}$ & $\mathrm{C}_{44}$ & $E_{\min }$ & $E_{\max }$ \\
\hline $237 \mathrm{GPa}$ & $141 \mathrm{GPa}$ & $116 \mathrm{GPa}$ & $132 \mathrm{GPa}$ & $276 \mathrm{GPa}$ \\
\hline
\end{tabular}

\section{Crystal anisotropy}

This section focuses on crystal anisotropy modeling. The first part proposes a description of elastic constitutive equations for the single crystal. Then the polycrystal behavior is presented in the second part. The material constants used in the article are defined in this section.

\section{Crystal elasticity}

The global objective of the project is to analyze failure initiation mechanisms in RCF. Therefore, the developed model could be applied to rolling element bearings, gears, or railway tracks. For each application, the material microstructure could be different and composed of several constituents (for example, ferrite, austenite, and martensite in bearing steels). In this article, a material composed of a single constituent, ferrite (iron $\alpha$ ), is considered.

The elastic behavior of a body-centered cubic structure like ferrite crystals is called cubic elasticity. The cubic elasticity stiffness matrix [C] (Eq. [7]) is described by three independent constants $\mathrm{C}_{11}, \mathrm{C}_{12}$, and $\mathrm{C}_{44}$. In the literature, different constants can be found to model the ferrite behavior. The ones defined by Courtney (31) are used (Table 2) The behavior of the ferrite single crystal is anisotropic and, therefore, the measured Young's modulus depends on the loading direction. This Young's modulus is minimum when evaluated in the directions $x, y$, $z$, of the crystal coordinate system (directions $[1,0,0],[0,1,0]$, and $[0$, $0,1])$, and maximum when evaluated in the direction $[1,1,1]$ of the crystal (Table 2).

$$
\left\{\begin{array}{l}
\sigma_{x} \\
\sigma_{y} \\
\sigma_{z} \\
\tau_{y z} \\
\tau_{x z} \\
\tau_{x y}
\end{array}\right\}=\left[\begin{array}{llllll}
\mathrm{C}_{11} & \mathrm{C}_{12} & \mathrm{C}_{12} & 0 & 0 & 0 \\
\mathrm{C}_{12} & \mathrm{C}_{11} & \mathrm{C}_{12} & 0 & 0 & 0 \\
\mathrm{C}_{12} & \mathrm{C}_{12} & \mathrm{C}_{11} & 0 & 0 & 0 \\
0 & 0 & 0 & \mathrm{C}_{44} & 0 & 0 \\
0 & 0 & 0 & 0 & \mathrm{C}_{44} & 0 \\
0 & 0 & 0 & 0 & 0 & \mathrm{C}_{44}
\end{array}\right] \times\left\{\begin{array}{c}
\varepsilon_{x} \\
\varepsilon_{y} \\
\varepsilon_{z} \\
\gamma_{y z}=2 \varepsilon_{y z} \\
\gamma_{x z}=2 \varepsilon_{x z} \\
\gamma_{x y}=2 \varepsilon_{x y}
\end{array}\right\} .
$$

\section{Polycrystal behavior}

A polycrystal is composed of a number of randomly oriented grains. A polycrystal containing a sufficiently large number of anisotropic linear elastic grains with all possible orientations (polycrystal without texture) exhibits an isotropic behavior at the macroscopic scale. This macroscopic behavior (isotropic linear elasticity) is described by two constants: the bulk modulus $K$ and the shear modulus $G$, for example. As a method for calculating those two constants, strain can be assumed to be

Table 3. Voigt and Reuss constants.

\begin{tabular}{lcccccc}
\hline$G_{v}$ & $\mathrm{G}_{\mathrm{r}}$ & $K_{v}=K_{r}$ & $E_{v}$ & $E_{r}$ & $\nu_{v}$ & $v_{r}$ \\
\hline $88.8 \mathrm{GPa}$ & $74.0 \mathrm{GPa}$ & $173 \mathrm{GPa}$ & $228 \mathrm{GPa}$ & $194 \mathrm{GPa}$ & 0.281 & 0.313 \\
\hline
\end{tabular}

uniform in the aggregate (Voigt's method). Another method consists of assuming stress to be uniform (Reuss's method). For an aggregate composed of cubic crystals, those constants have been evaluated by Hill (32) and are expressed in Eqs. [8] and [9]

$$
\begin{gathered}
K_{v}=K_{r}=\frac{1}{3} \times\left(\mathrm{C}_{11}+2 \mathrm{C}_{12}\right) \\
G_{v}=\frac{1}{5} \times\left(\mathrm{C}_{11}-\mathrm{C}_{12}+3 \mathrm{C}_{44}\right) \frac{1}{G_{r}}=\frac{1}{5} \times\left(4 \mathrm{~S}_{11}-4 \mathrm{~S}_{12}+3 \mathrm{C}_{44}\right)
\end{gathered}
$$

The expression of the Young's modulus and Poisson's ratio can be deduced from the shear modulus and bulk modulus (Den Toonder, et al. (33)) and estimations can be obtained as for the material considered in the present article (Table 3). Reuss's and Voigt's theories give lower and upper bonds for the polycrystal Young's modulus (Besson, et al. (34)).

\section{Representative volume element analysis}

There are two key issues when modeling the crystal anisotropy: (1) evaluating whether the material model used for crystal elasticity is representative of the macroscopic behavior of the polycrystal and (2) determining the influence of the polycrystal size on its macroscopic behavior. In order to answer those two questions, the behavior of an aggregate of crystals, the RVE, is investigated. It should be noted that macroscopic engineering constants (i.e., Young's modulus, Poisson's ratio), except the bulk modulus, are scale dependent. If the RVE size is not large enough, these constants depend on the distribution of grain orientation. When increasing the RVE size, the values of these constants should become less sensitive to the grain orientation and converge on macroscopic values of the polycrystal. Examples of investigations on the influence of the size of the RVE can be found in Ranganathan and Ostojastarzewshi (35) and El Houdaigui, et al. (36).

In this section, differences between a $2 \mathrm{D}$ approach and a $3 \mathrm{D}$ approach are discussed.

\section{Numerical model and analysis method}

In order to evaluate the Young's modulus of the RVE, two numerical models (depicted in Fig. 7) are used. The crystal or grain shape corresponds to a polygon in the $2 \mathrm{D}$ approach (Fig. 7a) and to a cube in the 3D approach (Fig. 7b). It has been

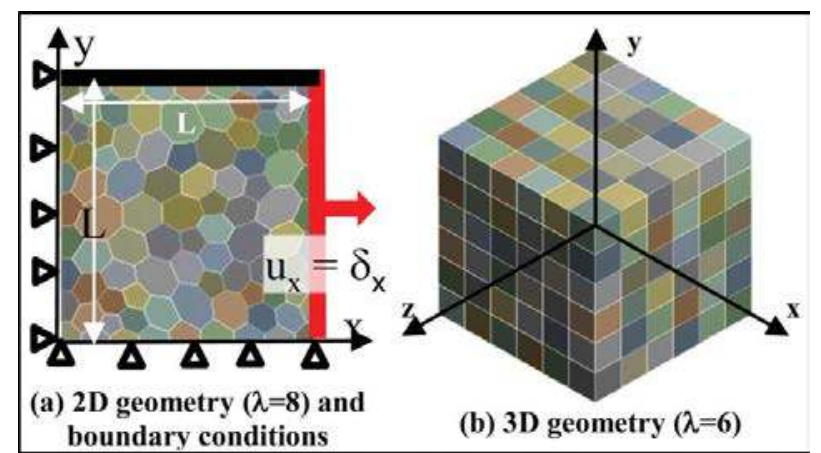

Figure 7. RVE models-2D approach and 3D approach. 


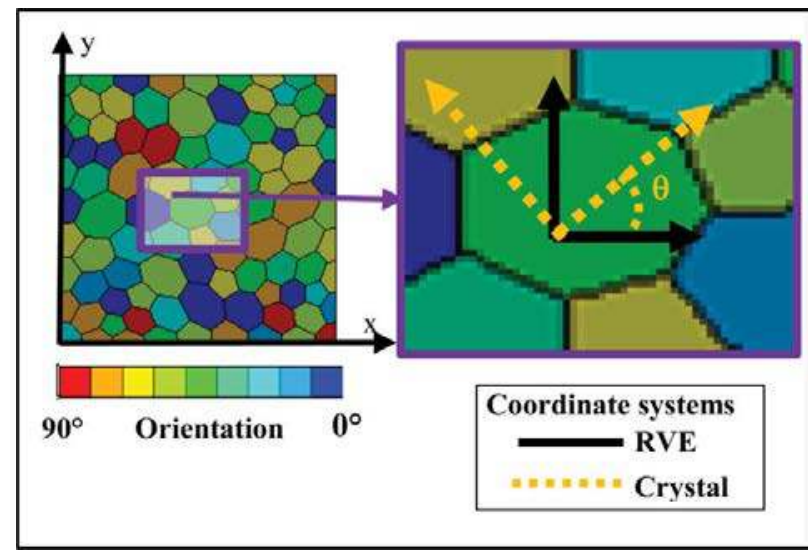

Figure 8. RVE 2D crystal orientation.

verified that the grain shape does not affect the macroscopic behavior. The RVE size is characterized by the dimensionless parameter $\lambda$, which is equal to the number of grains along each RVE edge.

The orientation of each grain in the RVE coordinate system is characterized by the three Euler's angles in the 3D approach and by the first Euler's angle in the 2D approach. Each angle is randomly defined between $0^{\circ}$ and $90^{\circ}$. An example of crystal orientation for the $2 \mathrm{D}$ approach is given in Fig. 8. The parameter $\theta$ corresponds to the first Euler's angle.

The method used to evaluate equivalent isotropic elasticity constants of the RVE is illustrated with the $2 \mathrm{D}$ approach. A uniaxial tension load case is simulated. Boundary conditions applied on the RVE are illustrated in Fig. 7a and Table 4. Concerning the 3D model, boundary conditions applied in the $z$ direction are similar to those applied in the $y$ direction.

Due to the boundary conditions applied on the RVE, the right and upper edges remain straight (Fig. 9). On the right edge, the displacement in the $x$ direction, $\delta_{x}$, is equal to the prescribed value ( $2 \mu \mathrm{m}$ in the example). On the upper edge, the resulting displacement in the $y$ direction, $\delta_{y}$, is constant and evaluated after the FEA $(0.326 \mu \mathrm{m}$ in the example). The reaction force $F_{x}$ due to the applied displacement $\delta_{x}$ is also evaluated after the FEA ( $352 \mathrm{~N}$ in the example).

Due to the random distribution of grain orientation, stresses and strains are not uniform in the RVE (Fig. 9). However, values of equivalent macroscopic stresses and strains can be defined and macroscopic engineering constants can be computed (Table 5).

\section{D approach: Results and discussion}

The preliminary step consists of investigating the influence of mesh size on the macroscopic behavior. The number of elements along a grain edge controls the mesh size. The Young's modulus and Poisson's ratio evaluated with three

Table 4. 2D boundary conditions.

\begin{tabular}{lcccc}
\hline Edge & $x=0$ & $y=0$ & $x=L$ & $y=L$ \\
\hline $\begin{array}{l}\text { Boundary conditions } \\
\text { Output }\end{array}$ & $U_{x}=0$ & $U_{y}=0$ & $U_{x}=\delta_{x}$ & $U_{y}$ free but constant \\
& & & Reaction force $F_{x}$ & $\delta_{y}$ \\
\hline
\end{tabular}

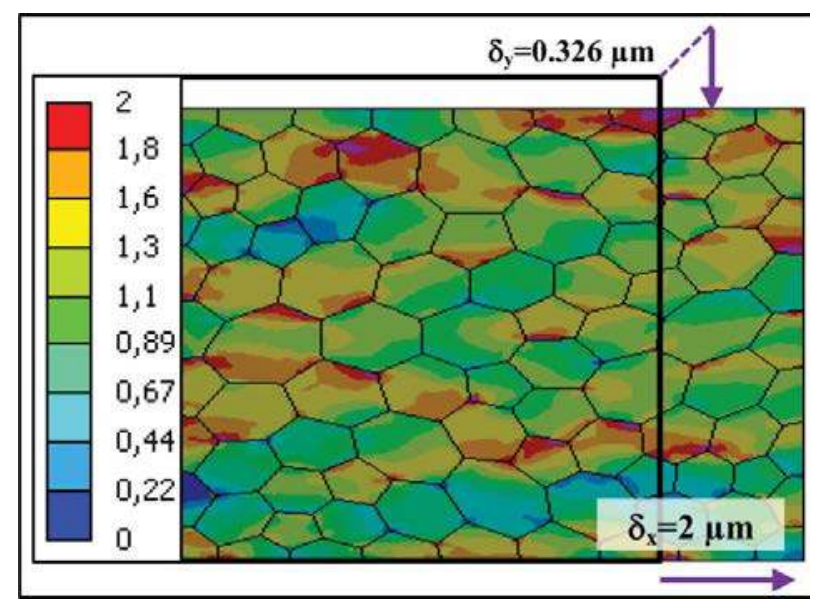

Figure 9. Mesoscopic normal stress, $\sigma_{x}$ distribution (MPa).

different meshes are listed in Table 6. These values depend slightly on the mesh so that a mesh with four elements along each edge will be used.

The influence of the RVE size on its macroscopic behavior is depicted in Fig. 10. The Young's modulus and Poisson's ratio have been evaluated for four RVE sizes: $\lambda=4,8,16$, and 32 . For each size, 10 simulations are performed with different random grain orientations. The results presented in Fig. 10 illustrate a substantial scattering around a mean value. Two conclusions can be drawn from these results: (1) as expected, when the RVE size increases, the scattering of the results decreases. With the greater size $(\lambda=32$, which corresponds to an RVE containing around 1,024 grains), the Young's moduli evaluated with each orientation are very close to each other; and (2) with regard to the values, the results are unexpected. The average value of the Young's modulus is around $170 \mathrm{GPa}$, less than the expected result: the Young's modulus of steel is known to be around $200 \mathrm{GPa}$. Moreover, the value should be between the Voigt value (228 GPa) and the Reuss value (194 GPa). Similar conclusions can be drawn with the Poisson's ratio, with an average value around 0.19 . An analysis of this unexpected result is given in the next paragraph.

Table 5. RVE equivalent properties.

\begin{tabular}{|c|c|c|}
\hline \multicolumn{3}{|l|}{ Macroscopic Components } \\
\hline \multicolumn{3}{|l|}{$\varepsilon_{x}=\frac{\delta_{x}}{L}=\frac{2 \mu \mathrm{m}}{200 \mu \mathrm{m}}=0.01$} \\
\hline \multicolumn{3}{|l|}{$\varepsilon_{y}=-\frac{\delta_{y}}{L}=-\frac{0.326 \mu \mathrm{m}}{200 \mu \mathrm{m}}=0.00163$} \\
\hline \multicolumn{3}{|l|}{$\sigma_{x}=\frac{\mathrm{F}_{x}}{A}=\frac{352 \mathrm{~N}}{0.2 \mathrm{~mm} 2}=1760 \mathrm{MPa}$} \\
\hline \multicolumn{3}{|c|}{ Macroscopic Engineering Constants Young's modulus: } \\
\hline \multicolumn{3}{|c|}{$E=\frac{\sigma_{x}}{\varepsilon_{x}}=176 \mathrm{GPa}$ Poisson's ratio: $\nu=-\frac{\varepsilon_{y}}{\varepsilon_{x}}=0.163$} \\
\hline Mesh: Number of Elements along Each GB & $E(\mathrm{GPa})$ & $v$ \\
\hline 2 & 176.09 & 0.1624 \\
\hline 4 & 176.00 & 0.1628 \\
\hline 8 & 175.98 & 0.1629 \\
\hline
\end{tabular}




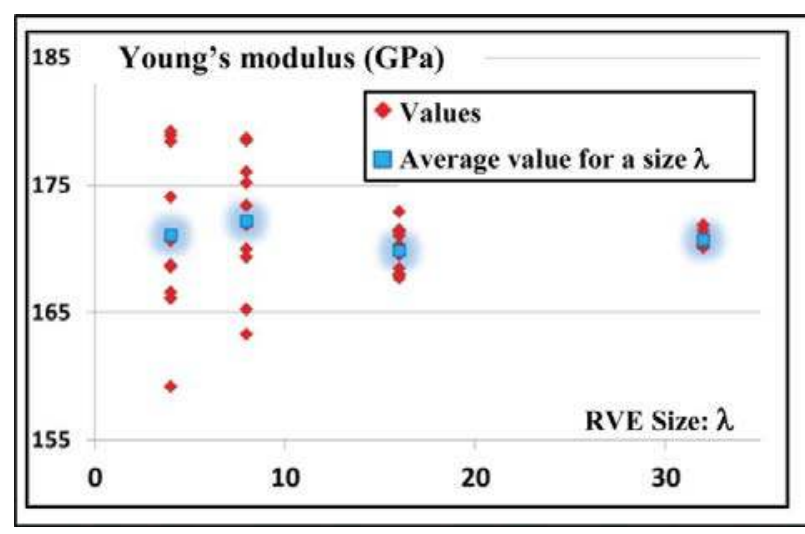

Figure 10. Young's modulus of the 2D RVE.

The load case used to evaluate the Young's modulus of the RVE corresponds to a uniaxial tensile load case. Therefore, the evaluated Young's modulus corresponds to the modulus in the $x$ direction of the RVE. The behavior of the single crystal is anisotropic and, therefore, its Young's modulus depends on the direction. For the material used in this article, the minimum value of this Young's modulus is $132 \mathrm{GPa}$ in the directions $x, y, z$ of the crystal coordinate system (directions $[1,0,0],[0,1,0]$, and $[0,0,1]$ ), and the maximum value is $276 \mathrm{GPa}$ in the direction $[1,1,1]$ of the crystal (Table 3). In the $2 \mathrm{D}$ approach presented in this subsection, crystal orientation is defined by only one rotation around the $z$-axis (Fig. 11). Therefore, the direction of the maximum Young's modulus does not appear in the 2D approach, which explains why the Young's modulus of the RVE is less than the expected value.

In order to justify the evaluated value of the RVE Young's modulus, $170 \mathrm{GPa}$, the influence of the $2 \mathrm{D}$ crystal orientation (parameter $\theta$ in Fig. 11) on crystal uniaxial behavior is analyzed. The crystal Young's modulus in the $x$ direction of the RVE is given in Eq. [10]. This equation comes from the classical formula used for general orthotropic composite materials (Berthelot (37)) and is adapted to cubic material. Figure 12 illustrates the evolution of that Young's modulus related to the crystal orientation (according to Eq. [10]). The maximum value is $221 \mathrm{GPa}$ when $\theta$ is equal to $45^{\circ}$. The average value around $170 \mathrm{GPa}$ for the RVE Young's modulus is in accordance with the curve represented in Fig. 12: the Young's modulus of each

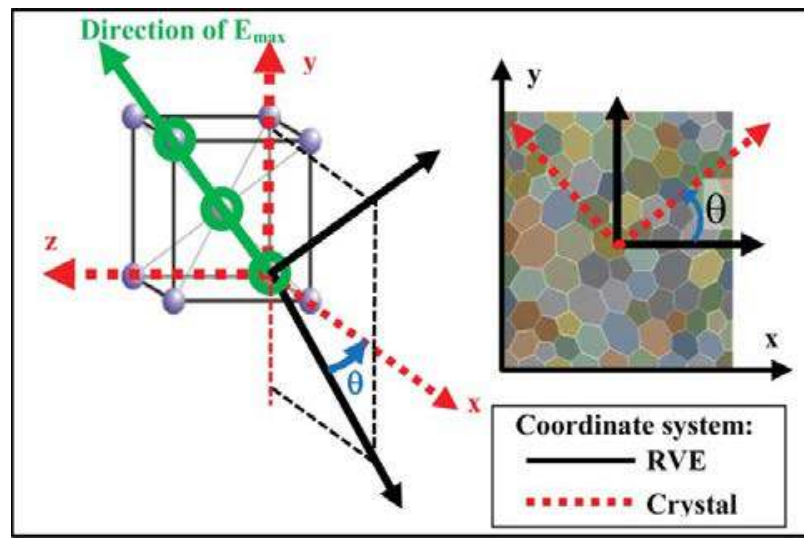

Figure 11. Crystal and RVE coordinate system.

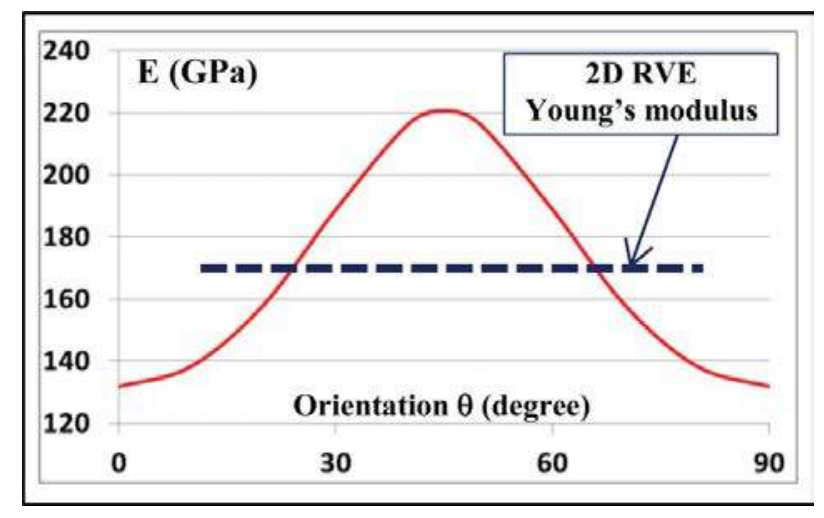

Figure 12. Influence of orientation on the crystal Young's modulus.

crystal in the $x$ direction of the RVE is greater than $132 \mathrm{GPa}$ and less than $221 \mathrm{GPa}$.

$$
\frac{1}{E_{x}(\theta)}=\left(\frac{\cos ^{4} \theta}{E}+\frac{\sin ^{4} \theta}{E}+\cos ^{2} \theta \sin ^{2} \theta \times\left(\frac{1}{G}-2 \frac{\nu}{E}\right)\right) .
$$

\section{D approach: Results and discussion}

The influence of the RVE size on its macroscopic behavior is depicted in Fig. 13. As with the 2D approach, the scattering decreases when the size increases, but the average value is in accordance with the expected value. With an RVE size corresponding to $\lambda=12$, the average value of the Young's modulus is equal to $207.5 \mathrm{GPa}$ and the Poisson's ratio is around 0.3. Therefore, the material constants defined in are representative of the macroscopic behavior of a polycrystal.

\section{D approach: Influence of the load case}

The actual RCF model is a $2 \mathrm{D}$ model, but previous subsections on the RVE behavior illustrate the limitations of a $2 \mathrm{D}$ model. Nevertheless, the evaluated Young's modulus depends strongly on the load case when the $2 \mathrm{D}$ approach is used. The load case used in the previous $2 \mathrm{D}$ approach corresponds to a uniaxial $(x$ direction) tensile load case and the evaluated macroscopic Young's modulus depends only on the crystal behavior (crystal Young's modulus) in the $x$ direction of the RVE. In order to be dependent on the crystal behavior in all directions, the

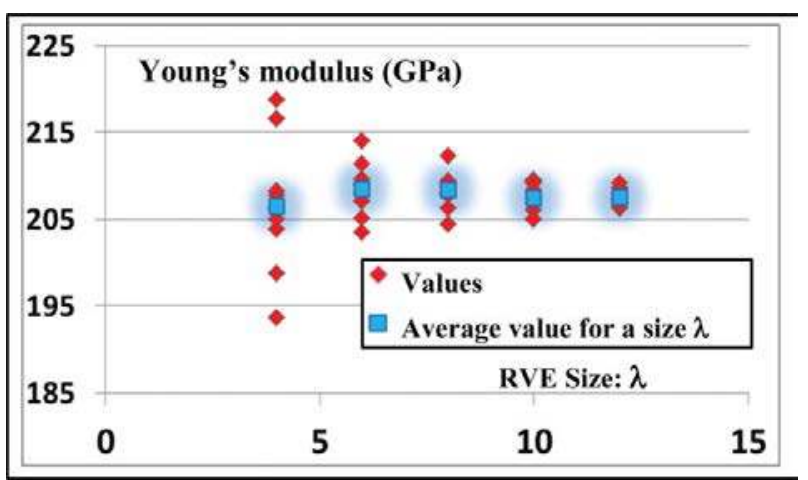

Figure 13. Young's modulus of the 3D RVE. 


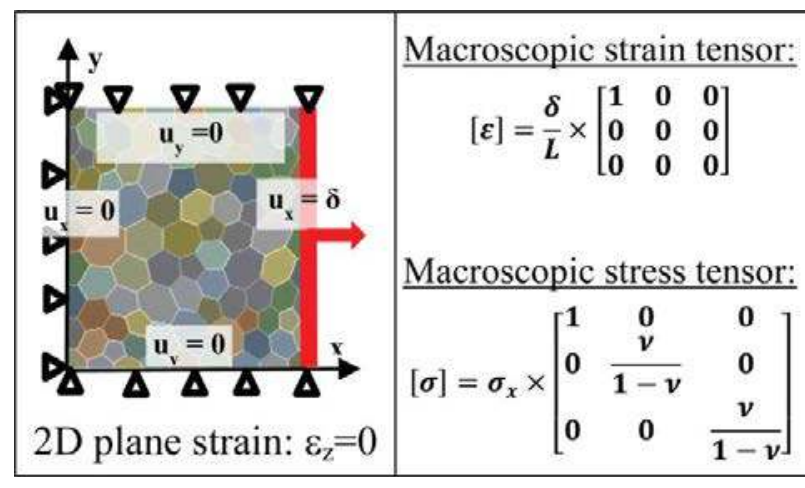

Figure 14. 2D approach-triaxial tensile load case.

macroscopic Young's modulus is evaluated with the triaxial tensile load case illustrated in Fig. 14.

The RVE Young's moduli evaluated with this load case are summarized in Fig. 15. These values are closer to the values from the 3D approach. Yet, in that load case, the modulus of the RVE depends on the crystal modulus in the three directions. Even if not all grain orientations are represented in the current 2D RCF model, the global behavior can be considered representative of the real behavior, and the influence of cubic elasticity will be investigated in the next section.

\section{Application of crystal anisotropy to the RCF model}

The cubic elasticity material model analyzed in the previous section is implemented in the RCF model. The orientation of each grain of the granular area is randomly defined.

\section{Influence of anisotropic elasticity}

The influence on the global behavior (displacement) is first analyzed and then the influence on local behavior (stress) is analyzed. An undamaged model with a Hertzian pressure centered on the granular area is used for this analysis.

As expected, anisotropy has almost no influence on the global behavior of the structure. Deformations (in the $y$ direction in the Fig. 16) are similar assuming isotropic elasticity or assuming anisotropic elasticity. Indeed, in the previous section, the global behavior of a 2D RVE subject to a triaxial tensile

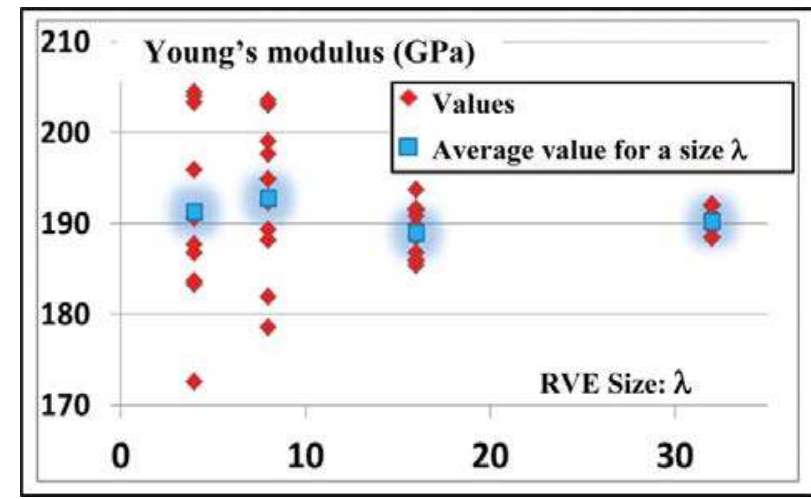

Figure 15. Young's modulus of the 2D RVE-triaxial load case.

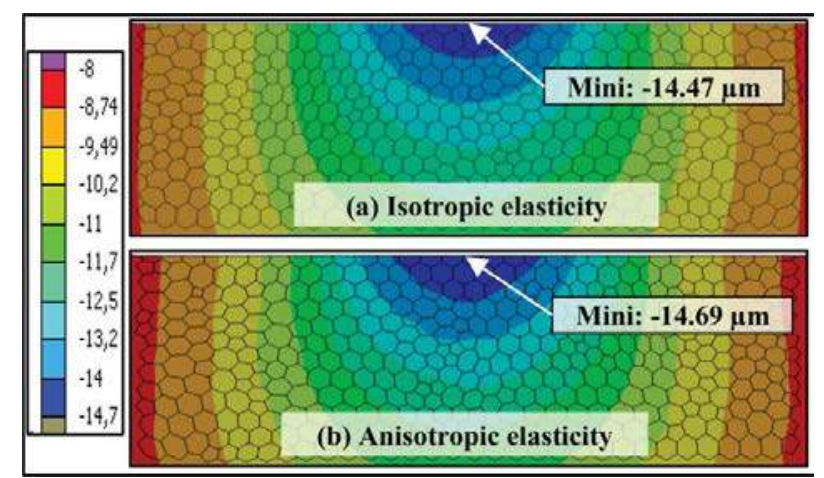

Figure 16. Vertical (y direction) displacements $(\mu \mathrm{m})$.

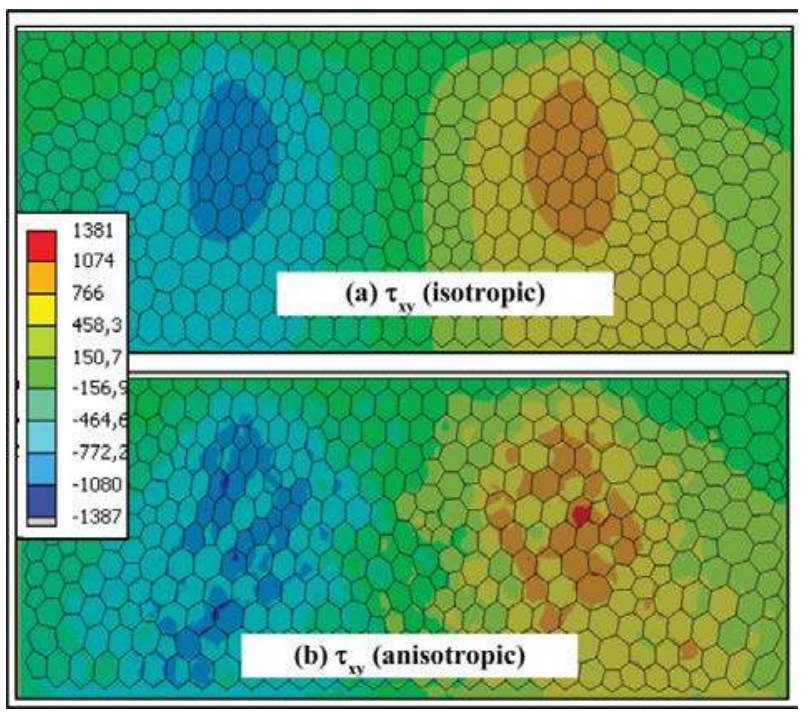

Figure 17. Influence of anisotropy on shear stress (MPa).

load case is close to the macroscopic behavior. Moreover, anisotropic elasticity is applied only on the granular area, which represents a small part of the model, which explains the small difference with isotropic modeling.

At the grain scale, anisotropic elasticity generates a heterogeneous stress distribution on the local behavior (Fig. 17). The maximum stress values are higher with anisotropy than with isotropy and concentrated near grain boundaries and particularly at triple junctions.

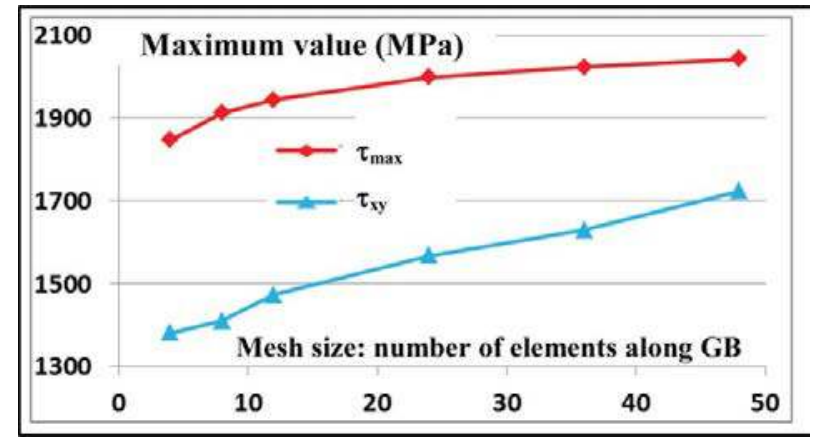

Figure 18. Influence of mesh size on maximum stresses. 


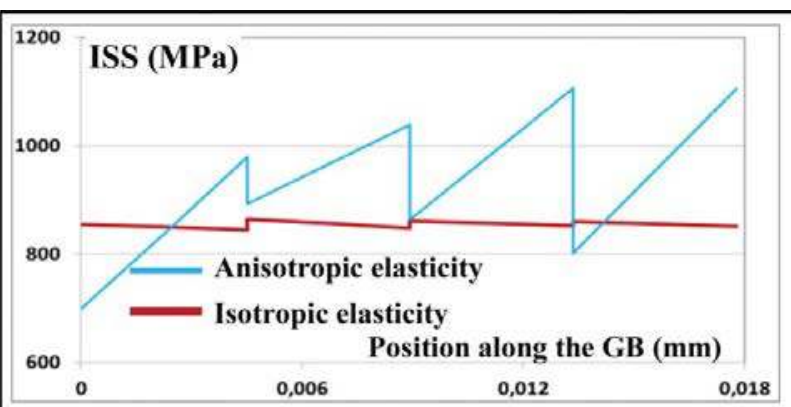

(a) ISS along the GB (at Time $=0.35$ )

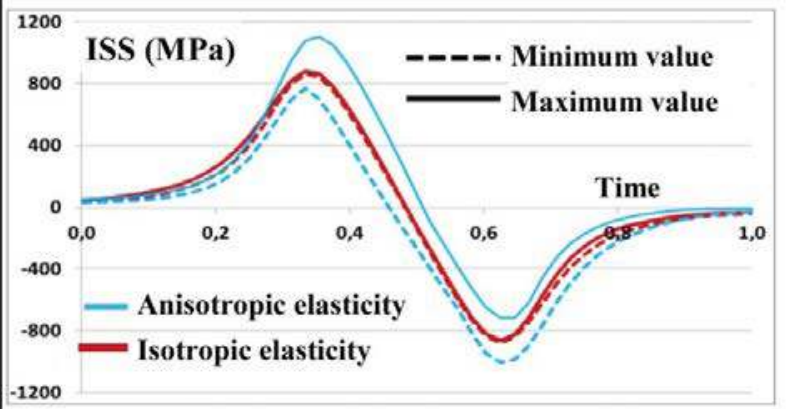

(b) Evolution of the ISS during the FEA

Figure 19. Influence of anisotropy on shear stress.

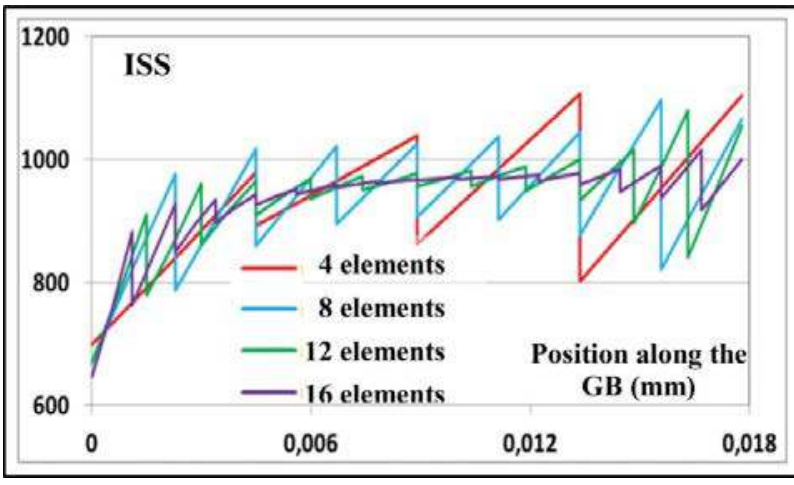

Figure 20. Mesh influence on ISS.

\section{Analysis of mesh size influence}

The previous analysis concerning mesh size demonstrated its low influence on the global behavior of the RVE. However, no investigations were performed regarding the influence on the local
Table 7. Influence of mesh size on the average value of the ISS.

\begin{tabular}{lcccc}
\hline Mesh Size: Number of Elements along the GB & 4 & 8 & 12 & 16 \\
\hline Average value of ISS (MPa) & 935.7 & 937.5 & 938.1 & 937.1 \\
\hline
\end{tabular}

behavior. This section focuses on the influence of mesh size on (1) the local stress in the solid and (2) the ISS along the GB.

Anisotropy generates stress concentrations at triple junctions as illustrated in Fig. 17b. Figure 18 shows the evolution of the maximum values of the shear stresses (orthogonal and maximum) depending on the mesh size. The maximum values of those shear stresses do not reach a plateau when increasing the number of elements. With anisotropic elasticity, stress singularities appear at triple junctions. This phenomenon was investigated in the past. For example, Tvergaard and Hutchinson (38) analyzed stress singularities at triple junctions of polycrystalline ceramics. They showed that triple junctions exhibit a singularity when the ceramic is subject to anisotropic thermal expansion. They also demonstrated that anisotropic elasticity could generate stress singularities. Recently, Fallahi and Ataee (39) investigated the influence of crystal orientation on stress distribution near a triple junction by a finite element approach.

In the present approach, the damage criterion is computed not with the solid stress but with the ISS and particularly with the average value of this ISS (Fig. 4). In order to determine the influence of the mesh size on the ISS, the first rolling contact cycle is simulated. Because only the first FEA cycle is performed, the structure is undamaged.

Results evaluated with a mesh size corresponding to four elements along each GB are presented in Fig. 19. A GB located in the area of maximum orthogonal shear stress (isotropic elasticity) is analyzed. Distribution of this ISS at Time $=0.35$ is illustrated in Fig. 19a. Anisotropy generates an irregular distribution along the GB. Figure 19b depicts the evolution of the maximum and minimum value of the ISS along this grain boundary during the first FEA.

The influence of the mesh size on this distribution is illustrated in Fig. 20. By increasing the number of elements along the GB, the distribution becomes smoother in the center of the GB; however, stress singularities can still be observed at triple junctions. The average values of the ISS are summarized in Table 7. This average value appears to be globally independent of the mesh size and can therefore be used as a damage

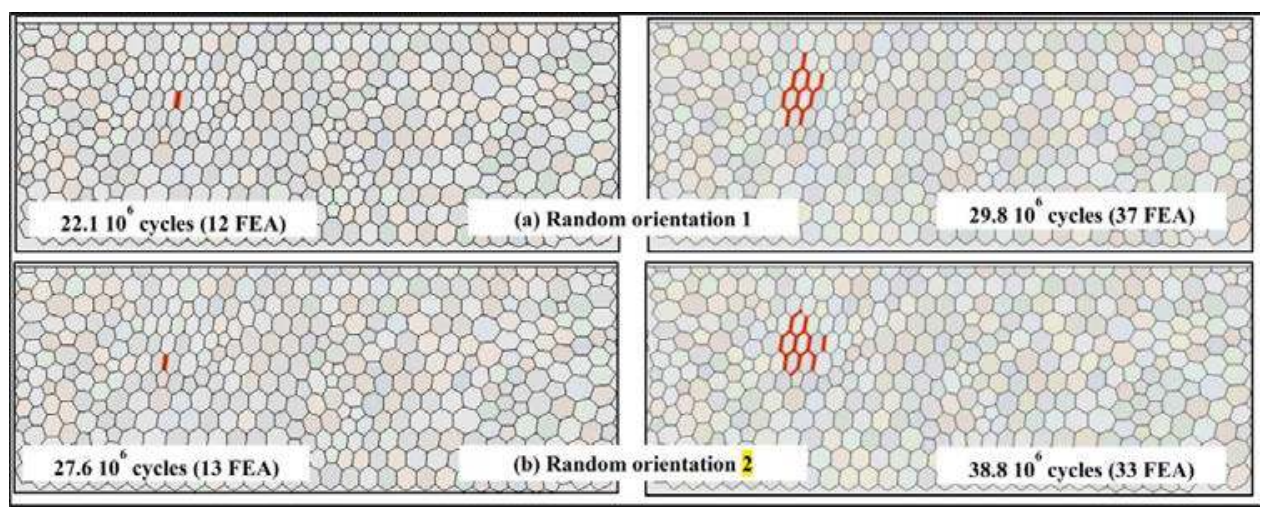

Figure 21. Microcrack distribution-influence of anisotropy. 


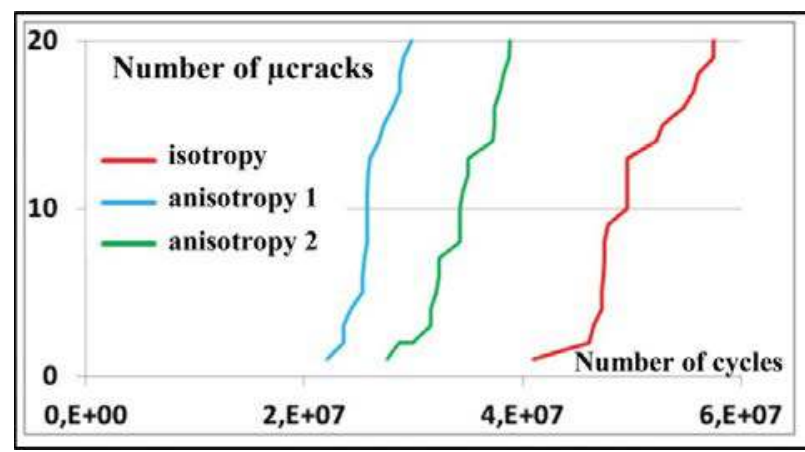

Figure 22. Life cycles.

criterion. To conclude, anisotropic elasticity could be implemented in the model despite stress singularities at triple junctions, and a mesh with four elements along each GB will be used with a sufficient level of accuracy.

\section{Influence of crystal anisotropy on cracks initiation}

Two simulations have been performed that differ by a different random grain orientation. Figure 21 illustrates the distribution of microcracks obtained with both simulations. For each simulation, the first microcrack is associated with a different grain boundary, but it is always located in the area of maximum orthogonal shear stress. Moreover, after coalescence of several microcracks, distributions are similar considering crystal anisotropy (Fig. 21) or assuming isotropic elasticity (Fig. 6).

Figure 21 highlights the weak effect of crystal anisotropy on microcrack distribution. However, the number of cycles corresponding to the appearance of microcracks is strongly influenced by crystal anisotropy (Fig. 22): (1) by increasing the stress in the structure, the introduction of anisotropic elasticity decreases the number of cycles corresponding to microcrack initiation and (2) the scattering results due to different grain orientation are representative of fatigue behavior. Therefore, anisotropic elasticity has to be included in future developments of the model.

\section{Conclusion}

This article focuses on the implementation of crystal anisotropy in a numerical granular cohesive RCF model. The analysis of a 3D RVE proves that constants used for the cubic elasticity model are representative of the elastic macroscopic behavior of steel. With regard to implementation of cubic elasticity in the RCF model, the stress distribution is very different from isotropic elasticity and is highly mesh dependent. This mesh dependency comes from the generation of stress singularities at triple junctions. Nevertheless, the damage criterion used in the model is computed not from solid stresses but from the average value of ISS. This last value has been proved to be globally mesh independent and therefore can be used as a damage criterion. Finally, the influence of crystal anisotropy on life cycle has been highlighted and the scattering results are representative of the fatigue behavior. Therefore, anisotropy has to be taken into account in future developments of the model.

The modeling of grain anisotropy is one of the first improvements of the initial model to make it as representative as possible of reality. The development of the model has to be continued. Future investigations will concern the modeling of grain behavior (influence of plasticity, for example) or damage modeling: in the current model, damage material parameters have been extracted from a torsion signal-to-noise curve and are therefore are representative of a macroscopic scale. The use of those parameters at the mesoscopic scale has to be validated or modified. Experimental validation is an important stage in the development of the model. However, RCF depends on a large number of parameters and the current model is a "perfect" model, without friction, surface roughness, or material heterogeneities. Therefore, those defects have to be modeled so that the numerical results can be compared with experimental results. This will be a next stage in the project.

\section{References}

(1) Sadeghi, F., Jalalahmadi, B., Slack, T. S., Raje, N., and Arakere, N. K. (2009), “A Review of Rolling Contact Fatigue," Journal of Tribology, 131(4), 041403.

(2) Olver, A. V. (2005), "The Mechanism of Rolling Contact Fatigue: An Update," Proceedings of the Institution of Mechanical Engineers Part J: Journal of Engineering Tribology, 219(5), pp 313-330.

(3) Keer, L. M. and Bryant, M. D. (1983), "A Pitting Model for Rolling Contact Fatigue," Journal of Lubrication Technology, 105(2), pp 198205.

(4) Trollé, B., Baietto, M.-C., Gravouil, A., Mai, S. H., and Prabel, B. (2014), "2D fatigue Crack Propagation in Rails Taking into Account Actual Plastic Stresses," Engineering Fracture Mechanics, 123, pp 163-181.

(5) Pierres, E., Baietto, M.-C., and Gravouil, A. (2011), "Experimental and Numerical Analysis of Fretting Crack Formation Based on 3D X-FEM Frictional Contact Fatigue Crack Model," Comptes Rendus Mécanique, 339(7-8), pp 532-551.

(6) Raje, N., Slack, T., and Sadeghi, F. (2009), "A Discrete Damage Mechanics Model for High Cycle Fatigue in Polycrystalline Materials Subject to Rolling Contact," International Journal of Fatigue, 31(2), pp 346-360.

(7) Blal, N., Daridon, L., Monerie, Y., and Pagano, S. (2012), "Artificial Compliance Inherent to the Intrinsic Cohesive Zone Models: Criteria and Application to Planar Meshes," International Journal of Fracture, 178(1-2), pp 71-83.

(8) Sauzay, M. (2006), "Effet de l'Anisotropie Élastique Cristalline sur la Distribution des Facteurs de Schmid à la Surface des Polycristaux" ("Influence of crystalline elasticity anisotropy on Schmid factor distribution at the free surface of polycrystals"), Comptes Rendus Mécanique, 334(6), pp 353-361.

(9) Paulson, N. R., Bomidi, J. A. R., Sadeghi, F., and Evans, R. D. (2014), "Effects of Crystal Elasticity on Rolling Contact Fatigue," International Journal of Fatigue, 61, pp 67-75.

(10) Alley, E. S. and Neu, R. W. (2010), "Microstructure-Sensitive Modeling of Rolling Contact Fatigue," Interntaional Journal of Fatigue, 32 (5), pp 841-850.

(11) Romero de la Osa, M., Estevez, R., Olagnon, C., Chevalier, J., and Tallaron, C. (2009), "Modèle Cohésif pour la Propagation Lente de Fissures dans les Céramiques Polycristallines" ("Cohesive zone model and slow crack growth in ceramic polycrystals"), Congrès Français de Mécanique, Marseilles, France, August 24-28.

(12) Estevez, R., Romero de la Osa, M., Olagnon, C., and Chevalier, J. (2010), "Cohesive Zone Description and Analysis of Slow Crack Growth in Ceramics," 13th International Conference on Fracture, Beijing, China, January 4-8.

(13) Warner, D. H. and Molinari, J. F. (2006), "Micromechanical Finite Element Modeling of Compressive Fracture in Confined Alumina Ceramic," Acta Materialia, 54(19), pp 5135-5145.

(14) Bomidi, J. A. R., Weinzapfel, N., Sadeghi, F., Liebel, A., and Weber, J. (2013), “An Improved Approach for 3D Rolling Contact Fatigue 
Simulations with Microstructure Topology," Tribology Transactions, 56(3), pp 385-399.

(15) Bhargava, V., Hahn, G. T., and Rubin, C. A. (1990), "Rolling Contact Deformation, Etching Effects, and Failure of High-Strength Bearing Steel," Metallurgical Transactions A, 21, pp 1921-1931.

(16) Warhadpande, A., Sadeghi, F., Evans, R. D., and Kotzalas, M. N. (2012), "Influence of Plasticity-Induced Residual Stresses on Rolling Contact Fatigue," Tribology Transactions, 55(4), pp 422-437.

(17) Xu, X.-P. and Needleman, A. (1994), "Numerical Simulations of Fast Crack Growth in Brittle Solids," Journal of the Mechanics and Physics of Solids, 42(9), pp 1397-1434.

(18) Nguyen, O., Repetto, E. A., Ortiz, M., and Radovitzky, R. A. (2001), "A Cohesive Model of Fatigue Crack Growth," International Journal of Fracture, 110, pp 351-359.

(19) Luther, T. and Könke, C. (2009), "Polycrystal Models for the Analysis of Intergranular Crack Growth in Metallic Materials," Engineering Fracture Mechanics, 76(15), pp 2332-2343.

(20) ANSYS (2012), ANSYS ${ }^{\circledR}$ Academic Research, Release 14.5, Help System Contact Technology Guide, ANSYS Inc.: Canonsburg, PA.

(21) Espinosa, H. D. and Zavattieri, P. D. (2003), "A Grain Level Model for the Study of Failure Initiation and Evolution in Polycrystalline Brittle Materials. Part I: Theory and Numerical Implementation," Mechanics of Materials, 35(3-6), pp 333-364.

(22) Noyel, J. P., Ville, F., Jacquet, P., and Gravouil, A. (2014), "Development of a Granular Cohesive Model for Rolling Contact Fatigue Analysis: Influence of Numerical Parameters," International Gear Conference 2014, Lyon, France, August 26-28, P. Velex (Ed.), International Gear Conference 2014: 26th-28th August 2014, Lyon, pp 814-824, Elsevier: Cambridge, UK.

(23) Kachanov, L. (1986), Introduction to Continuum Damage Mechanics, Martinus Nijhoff Publishers: Dordrecht, Netherlands.

(24) Lemaitre, J., Chaboche, J. L., Benallal, A., and Desmorat, R. (2009), Mécanique des Matériaux Solides (Mechanics of solid materials), 3rd ed. Dunod: Paris, France.

(25) Lemaitre, J. and Desmorat, R. (2005), Engineering Damage Mechanics, Springer: Berlin, Germany.

(26) Longching, C., Qing, C., and Eryu, S., (1989), "Study on Initiation and Propagation Angles of Subsurface Cracks in GCr15 Bearing Steel under Rolling Contact," Wear, 133, pp 205-218.

(27) Qing, C., Eryu, S., Dongmei, Z., Juwen, G., and Fan, Z. (1991), "Measurement of the Critical Size of Inclusions Initiating Contact Fatigue Cracks and Its Application in Bearing Steel," Wear, 147, pp 285-294.
(28) Nélias, D., Dumont, M. L., Champiot, F., Vincent, A., Girodin, D., Fougères, R., and Flamand, L. (1999), "Role of Inclusions, Surface Roughness and Operating Conditions on Rolling Contact Fatigue," Journal of Tribology, 121(2), pp 240-251.

(29) Rabaso, P., Gauthier, T., Diaby, M., and Ville, F. (2013), "Rolling Contact Fatigue: Experimental Study of the Influence of Sliding, Load, and Material Properties on the Resistance to Micropitting of Steel Discs," Tribology Transactions, 56(2), pp 203-214.

(30) Allison, B., Subhash, G., Arakere, N., Haluck, D. A., and Chin, H. (2014), "Influence of Initial Residual Stress on Material Properties of Bearing Steel during Rolling Contact Fatigue," Tribology Transactions, 57(3), pp 533-545.

(31) Courtney, T. H. (1990), Mechanical Behavior of Materials, 2nd ed. McGraw Hill: Long Grove, IL.

(32) Hill, R. (1952), "The Elastic Behaviour of a Crystalline Aggregate," Proceedings of the Physical Society Section A, 65, pp 349-354.

(33) Den Toonder, J. M. J., Van Dommelen, J. A. W., and Baaijens, F. P. T. (1999), "The Relation between Single Crystal Elasticity and the Effective Elastic Behaviour of Polycrystalline Materials: Theory, Measurement and Computation," Modelling and Simulation in Materials Science and Engineering, 7(6), pp 909-928.

(34) Besson, J., Cailletaud, G., Chaboche, J. L., and Forest, S. (2001), Mécanique Non Linéaire des Matériaux (Non-Linear Mechanics of Materials), Hermes: Paris, France.

(35) Ranganathan, S. and Ostojastarzewski, M. (2008), "Scaling Function, Anisotropy and the Size of RVE in Elastic Random Polycrystals," Journal of the Mechanics and Physics of Solids, 56(9), pp 2773-2791.

(36) El Houdaigui, F., Forest, S., Gourgues, A. F., and Jeulin, D. (2005), "On the Size of the Representative Volume Element for Isotropic Elastic Polycrystalline Copper," IUTAM Symposium, Beijing, China, June 27-30, Y. L. Bai, Q. S. Zheng, and Y. G. Wei (Eds.) IUTAM Symposium on Mechanical Behavior and Micro-Mechanics of Nanostructured Materials, pp 171-180, Springer: Amsterdam.

(37) Berthelot, J. M. (2005), Matériaux Composites (Composite Materials), 4th ed. Lavoisier: Paris.

(38) Tvergaard, V. and Hutchinson, J. W. (1998), "Microcracking in Ceramics Induced by Thermal Expansion or Elastic Anisotropy," Journal of the American Ceramics Society, 71, pp 3157-166.

(39) Fallahi, A. and Ataee, A. (2010), "Effects of Crystal Orientation on Stress Distribution Near the Triple Junction in a Tricrystal $\gamma$-TiAl," Materials Science and Engineering A, 527(18-19), pp 4576-4581. 